1 ANALYTICAL SCIENCE

3 \& TECHNOLOGY

Vol. 26, No. 1, 27-33, 2013

http://dx.doi.org/10.5806/AST.2013.26.1.027

\title{
Synthesis of poly(dialkyl or monoalkyl)silanes as silicon carbide precursors for ceramic matrix composites
}

\author{
Gyu-Hwan Lee
}

Department of Chemistry, Hannam University 461-6 Jeonmin-dong, Yusung-ku, Daejeon 305-811, Korea (Received November 30, 2012; Revised December 6, 2012; Accepted December 6, 2012)

\section{탄화규소 선구물질로서의 폴리(디알킬 또는 모노알킬)실란들의 합성과 세라믹 복합체 응용}

이 규 환`

한남대학교 화학과

(2012. 11. 30. 접수, 2012. 12. 6. 수정, 2012. 12. 6. 승인)

\begin{abstract}
Polyalkylsilanes such as poly(dialkyl)silanes and poly(monoalkyl)silanes were synthesized by sonochemical dechlorination-condensation method from (dialkyl or monoalkyl)chlorosilanes with sodium metal. Those polyalkylsilanes were analyzed for the properties such as thermal behaviors from TGA analysis and obtained ceramic yields of $10-20 \%$ for poly(dialkyl)silanes and $40-60 \%$ for poly(monoalkyl)silanes. Ceramic composite discs were prepared by the combined mixture of polyalkylsilanes and $\mathrm{SiC}$ powder and were tested by TGA and analyzed by SEM and XRD for the application as binder for ceramic composite precursors.

요 약: 유기염화실란을 출발물질로 사용하고 초음파 반응 방법을 이용하여 알칼리 금속과 반응시켜 탈 염소축합반응으로 폴리(디알킬)실란과 폴리(모노알킬)실란 등의 폴리알킬실란들을 합성하고 이들의 열적 성질을 TGA로 조사하여 각각 $10-20 \%$ 와 $40-60 \%$ 의 잔류물 수득률을 얻었고 상업용 $\mathrm{SiC}$ 분말과 함께 펠 렛 디스크를 성형하여 열분해 과정과 $\mathrm{SEM}, \mathrm{XRD}$ 등으로 세라믹 복합체 응용 가능성을 조사하였다.
\end{abstract}

Key words: polyalkylsilane, poly(dialkyl)silane, poly(monoalkyl)silane, ceramic composite precursor, sonochemical synthesis

\section{1. 서 론}

폴리실란은 규소-규소 결합을 기본 골격으로 하고 유기치환기를 갖는 무기고분자 화합물의 하나로서 규 소-규소 결합의 골격 사슬을 따라 상당한 $\sigma$ 전자의
비편재화가 허용되어 있으며 이로 인해 강한 자외선 흡수 스펙트럼과 규소-규소 연속결합이 많을수록 흡 수 파장이 장파장으로 이동되는 현상이 나타난다. ${ }^{1-5}$ 폴리실란의 이러한 전자적 특성인 $\sigma-\sigma^{*}$ 전자전이 결 과 규소-규소 결합의 약화 및 끊어짐이 발생하게 되어

Corresponding author

Phone : +82-(0)42-629-8816 Fax : +82-(0)42-629-8811

E-mail : gyuhlee@gmail.com 
폴리실란이 광반응에 의한 전자재료로 이용되거나 광 감전도체 또는 비닐 고분자화반응의 반응개시제로서 활용이 기대되며 비선형광학성질, 세라믹 전구체 등의 목적으로도 활용이 가능하고, 비선형광학성질에 대해 서도 많은 연구가 수행되고 있다. ${ }^{4,5}$ 또한 이외에도 폴 리실란은 세라믹 전구체 등의 목적으로도 활용이 가 능하다. 최근에는 폴리실란의 전자적 성질을 이용하여 올리고실란의 고분자화를 통한 폴리실란의 형성하고 이를 이용한 태양전지용 박막 규소 또는 무정형 규소 $(a-\mathrm{Si})$ 또는 차세대 반도체용 박막트랜지스터의 원료 용 다결정성 규소 $(p-\mathrm{Si})$ 로 이용하고자 하는 많은 연 구가 수행되고 있다. ${ }^{1-3}$

폴리머 흡착과 열분해 과정은 탄화규소 $(\mathrm{SiC})$ 소재 와 같은 세라믹 복합체의 제조에서 넓게 사용되고 있 다. 이러한 목적에 맞는 고분자 물성으로 액체이거나 가용성이면서 안정하고 가교반응이 가능하거나 높은 열분해(세라믹) 수율을 가지면서 화학양론적 조성을 줄 수 있어야 한다. ${ }^{3}$ 일반적으로 염화실란의 금속 나 트륨과 같은 알칼리 금속을 이용한 Wurtz 탈염소 축 합반응을 이용한 규소-규소 결합의 형성이 탄화규소 선구물질의 제조방법의 하나로 인식되고 있는데 정제 된 고순도의 염화실란을 출발물질로 사용함으로서 고 품질의 탄화규소 복합체 제조가 가능하기 때문이다. 염화실란 화합물중 메틸트리염화실란으로부터 생성되 는 메틸폴리실란은 $\mathrm{C}: \mathrm{Si}$ 비가 1:1로서 탄화규소의 선 구물질로 이상적인 조성을 가지고 있지만 불용성 고 체로서 가공성이 매우 낮으며 열분해시 세라믹 수율 이 낮다는 것이 단점으로 지적되었으며, 디메틸디염화 실란으로부터 생성된 디메틸폴리실란은 $\mathrm{C}: \mathrm{Si}$ 비가 $2: 1$ 로서 탄소 잔류물의 가능성이 있지만 디메틸폴리실란 은 고온고압 반응기(autoclave)에서 열적 재배열 반응 인 Yajima 과정을 통해 가용성과 가공성이 우수한 폴 리카보실란을 형성하고 이 물질의 열분해를 통해 탄 화규소 섬유 등의 제품을 생산할 수 있다. 하지만 고 온 고압에서의 열적 재배열 반응이 제한적인 단점으 로 여겨진다.

본 연구에서는 비록 세라믹 수율에서의 감소가 예 상되지만 폴리실란의 합성이 비교적 용이하고 합성된 폴리실란의 물성이 가용성이면서 변형이 용이한 다양 한 폴리알킬실란을 금속 나트륨과 알킬염화실란과 같 은 유기화합물 사이의 불균일(heterogenous) 반응에 효과적으로 받아들여진 초음파 화학적 반응 방법을 이용하여 비교적 용이하고 효율적으로 합성하고 이러 한 폴리알킬실란을 열적 재배열과 같은 2 차 과정을
통하지 않고 폴리머 흡착을 통한 세라믹 복합체에 이 용할 수 있는지 조사하였다.

$$
\begin{aligned}
& \mathrm{R}_{2} \mathrm{SiCl}_{2} \underset{<<<}{\stackrel{\mathrm{Na}}{\longrightarrow}}-\left[\mathrm{R}_{2} \mathrm{Si}\right]_{\mathrm{n}}- \\
& \mathrm{RSiCl}_{3} \underset{<<<}{\stackrel{\mathrm{Na}}{\longrightarrow}}-[\mathrm{RSi}]_{\mathrm{n}}-
\end{aligned}
$$

현재까지 유기 치환기를 하나 포함하고 있거나 전 혀 포함하고 있지 않은 염화실란의 금속 나트륨을 사용한 탈염소화축합 반응은 별로 많이 연구되어지지 않았는데 그 주된 이유는 생성물이 대부분 불용성 고 체를 주기 때문이었다. 규소-규소 결합의 형성은 규소 -염소 결합으로부터 이루어지는데 디유기디염화실란 $\left(\mathrm{R}_{2} \mathrm{SiCl}_{2}\right)$ 같은 경우에는 선형 또는 고리형 구조의 폴 리실란 형성이 가능하지만 트리염화실란 $\left(\mathrm{RSiCl}_{3}\right)$ 같이 규소-염소 결합이 분자 당 3 개인 경우에는 3 차원 네 트워크 구조의 고분자성 규소-규소 결합이 형성되어 유기 치환기가 있다고 해도 이들 규소-규소 결합의 무 기적 성질에 의해 고체 생성물이 얻어지는 것으로 설 명할 수 있다.

1975년 Yajima는 결정성의 폴리디메틸실란을 고 온고압에서 열적 재배열시켜 폴리카보실란을 얻는 공정을 발표하였는데 폴리카보실란은 폴리디메틸실 란과 다르게 용매에 녹고 열을 가해도 녹는 가공성 을 가지고 있어 이로부터 탄화규소 섬유, 박막 등의 세라믹제품을 얻을 수 있었다. ${ }^{9-11}$ 그 이후 가용성 폴 리실란의 연구가 활발해 졌는데 그 일부를 보면 폴 리메 틸페닐실란, 폴리디메틸디페닐실란 공중합체, 폴 리실라스티렌 등이 있으며 페닐기의 도입으로 메틸 기만의 높은 결정성을 깨고 가용성, 열연화성 성질 을 부여하는 것으로 보고되었다. 그 이후 폴리카보 실란과 폴리실란의 구조를 함께 갖는 폴리실라메틸 레노실란이 개발되어 새로운 목적의 물질로 발표되 었다. ${ }^{12,13}$

본 연구에서 폴리알킬실란의 합성에 이용한 초음파 반응 방법의 특성은 다음과 같다. 강한 세기의 초음파 는 여러 종류의 화학반응에 대해서 바람직한 결과를 주며, 특히 금속 표면이 반응에 참여하는 불균일계 화 학반응에 대한 증진효과가 큰 것으로 알려져 있고 근 래에 폴리실란의 새로운 합성방법으로 초음파를 이용 한 연구가 많이 진행되고 있다. ${ }^{13}$ 초음파 반응의 특징 은 용매 증기 방울(bubble)의 생성, 팽창, 폭축에 의해 나타나며 반응의 선택성 증가, 반응시간의 감소, 금속 활성의 증가 등의 효과를 주고 특히 불균일 반응에서 금속 표면의 계속적인 세척(sweeping)에 의해 반응 부 
위의 빠른 재생 효과를 준다. 뿐만 아니라, 용매 증기 방울의 붕괴가 일어나는 동안 상당히 높은 온도와 압 력이 발생하게 되는데 이로 인한 빠른 반응속도를 기 대할 수 있다.

\section{2. 실 험}

\section{1. 시약 및 기기}

본 실험에서 사용한 염화실란 화합물들은 공기 중 의 수분과 반응해서 가수분해 되기 때문에 공기 및 수분을 완전히 차단시키고 건조 질소 대기하의 실험 장치에서 수행하였다. 나트륨, 포타슘, 톨루엔, $n$-헥산, $\mathrm{THF}$ 등은 Aldrich Chemical 사와 동양화학 등의 제품 을 사용하였고 반응 출발물질인 사염화실란은 미국 Gelest 사의 제품을 증류하여 사용하였다. 반응에 용 매로 사용한 톨루엔, THF, $n$-헥산은 사용하기 전 나트 륨 하에서 증류 건조시켰으며, 반응 유리 기구들은 불 꽃으로 건조하였고 모든 실험은 질소 대기 하에서 수 행하였다.

합성에 쓰인 초음파 발생장치인 Sonifier는 Branson Co.의 Model 450 (Ultrasonic energy $20 \mathrm{KHz}$, Max. power 400Watt; 1/2" Flat horn tip)을 사용하였고, 모 든 반응물의 첨가는 건아 기전(주)의 Syringe Pump, Hamilton gas tight syringe와 Teflon needle $(30 \mathrm{~cm})$ 을 사용하였다.

각 반응을 통하여 합성된 폴리실란의 존재유무, 전 자적 특성은 Shimadzu UV-3101PC UV-Visble-NIR Scanning Spectrophotometer를 이용해 톨루엔, THF, 등을 용매로 하여 측정하였고 반응 완결 후 합성된 고 분자 물질 및 기타 시료의 주요 특성은 FT-IR (Thermo Scientific 사의 Nicolet iS10), ${ }^{1} \mathrm{H}-\mathrm{NMR}$ (Varian 사의 모 델 Gemini, $300 \mathrm{MHz}$ ), GPC (Waters 사의 모델 590 및 RI detetctor system과 Styragel column, $500,10^{3}, 10^{4} \AA$ 직렬 연결), TGA (Scinco사의 모델 TGA S-1000), SEM (SEC사의 mini-SEM SNE 4500M), XRD (Bruker $\mathrm{AXS}$ 사의 $\mathrm{D} 8 \mathrm{ADVANCE}$, 충남대학교 공동실습실험관) 등을 사용하여 조사하였다.

\section{2. 실험}

\subsection{1. 폴리알킬실란의 초음파화학적 합성}

폴리알킬실란 합성의 일반적인 경우로서 폴리(디-헥 실)실란의 합성은 다음과 같다. Fig. 1 과 같이 초음파 발생장치와 응축기가 장착된 $100 \mathrm{~mL} \mathrm{2}$ 구 둥근바닥 플라스크를 질소 대기 하로 유지하면서 불꽃 건조한

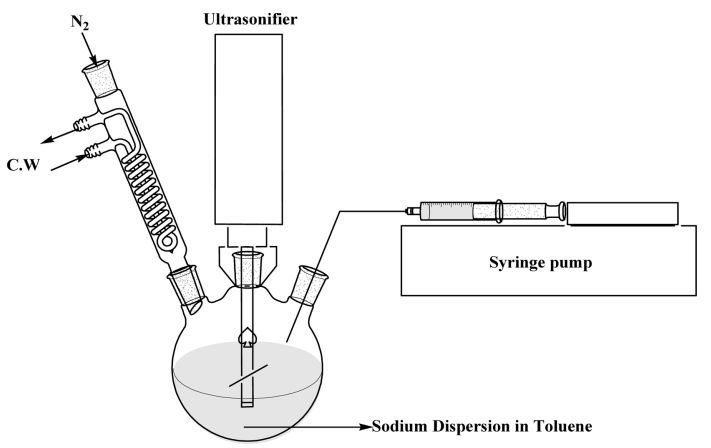

Fig. 1. Experimental apparatus for sonochemical preparation of poly(dialkyl or monoalkyl)silanes.

후 톨루엔 $50 \mathrm{~mL}$ 와 나트름 $2.0 \mathrm{~g}(87.0 \mathrm{mmol})$ 을 넣어 주고 초음파 장치를 15 분 정도 작동시켜 분산시켜 주 었다. 나트륨이 충분히 분산된 것을 확인 한 후 디헥 실디염화실란 $\left((n-\mathrm{Hexyl})_{2} \mathrm{SiCl}_{2}\right) 10.0 \mathrm{~g}(37.1 \mathrm{mmol})$ 을 gastight syringe와 syringe pump를 이용하여 약 10 분에 걸쳐 넣어 주고 첨가 후 약 30 분 동안 초음파 반응을 더 진행시켰다. 필요한 경우 기체크로마토그라피로 반 응물의 존재를 확인하여 반응물이 소진된 것을 확인 한 후 고분자 말단 폐쇄제(chain-endcapping agent)로 페닐디메틸염화실란 $\left(\mathrm{PhMe}_{2} \mathrm{SiCl}\right)$ 소량 $(0.5 \mathrm{~g})$ 을 첨가하 고 추가로 초음파 반응 장치를 20 분간 더 작동시켰다. 반응 생성물을 식혀서 과량의 나트륨을 에탄올과 증 류수로 처리하고 톨루엔 용액 층을 물 층으로부터 분 리한 후 무수 황산마그네슘으로 건조시키고 걸러서 용매를 제거하였다. 약간 노란색의 점도가 높은 오일 과 같은 생성물은 진공에서 2 시간 동안 더 건조하여 노란색의 반고체 $5.89 \mathrm{~g}(29.7 \mathrm{mmol}$ 수득률 $80.2 \%)$ 를 얻었다.

일반적으로 생성물에는 고분자량 성분과 저분자량 성분이 함께 존재하는데 고분자량 성분은 생성물을 다시 소량의 $n$-헥산에 녹인 다음 $i$-프로필알코올을 천 천히 첨가하면 흰색 고체가 형성되는 재결정을 통해 서 분리시킬 수 있었다. 이와 같은 재결정법으로 얻어 지는 흰색 고체 생성물은 $20-30 \%$ 이었다. 이와 같은 방법으로 얻어진 폴리알킬실란들의 결과를 Table 1에 정리하였으며 이들의 열적 성질을 질소 대기 하에서 TGA로 조사하였다(Fig. 2, 3).

폴리알킬실란의 세라믹 복합체 응용을 위해 상업용 $\mathrm{SiC}$ 분말과 폴리알킬실란을 일정 무게 비(2:1 또는 $1: 1$ )로 섞은 다음 소량의 $\mathrm{THF}$ 를 넣어 폴리알킬실란을 용해시켜서 $\mathrm{SiC}$ 분말과 잘 섞이게 한 다음 혼합물을 
Table 1. Syntheses of polyalkylsilanes by sonochemical method

\begin{tabular}{llccccc}
\hline \hline \multicolumn{1}{c}{$\mathrm{R}$} & $\begin{array}{c}\text { Total Yield } \\
(\%)\end{array}$ & $\begin{array}{c}\text { Av. Mw } \\
\text { (Major peak) }\end{array}$ & $\begin{array}{c}\lambda \max \\
(\mathrm{nm})\end{array}$ & $\begin{array}{c}\text { TGA } \\
\text { residue \% }\end{array}$ & Remark \\
\hline \multirow{6}{*}{$\mathrm{R}_{2} \mathrm{SiCl}_{2}$} & $\mathrm{CH}_{3}$, phenyl & 70.4 & $9 \times 10^{3}$ & 338 & 20.0 & \\
& $\mathrm{CH}_{3}, n$-hexyl & 88.8 & $3 \times 10^{3}$ & 327 & 11.0 & $*$ *liquid oil \\
& $\mathrm{CH}_{3}, n$-dodecyl & $* *$ & $5 \times 10^{3}$ & 318 & 10.7 & \\
& $n$-pentyl, $n$-pentyl & 75.6 & $1 \times 10^{4}$ & 325 & 20.9 & \\
& $n$-hexyl, $n$-hexyl & $80.2\left(72.0^{*}\right)$ & $3 \times 10^{4}$ & 314 & 17.4 & $* \mathrm{NaK}_{2}$ (others: Na) \\
& $n$-octyl, $n$-octyl & $* *$ & $2 \times 10^{4}$ & 320 & 12.0 & $*$ *liquid oil \\
\hline \multirow{2}{*}{$\mathrm{RSiCl}_{3}$} & $\mathrm{CH}_{3}$ & 48.1 & $8 \times 10^{3}$ & 273 & 66.5 & Insoluble solid formed \\
& phenyl & 90.8 & $3 \times 10^{3}$ & 291 & 47.1 & \\
\hline
\end{tabular}

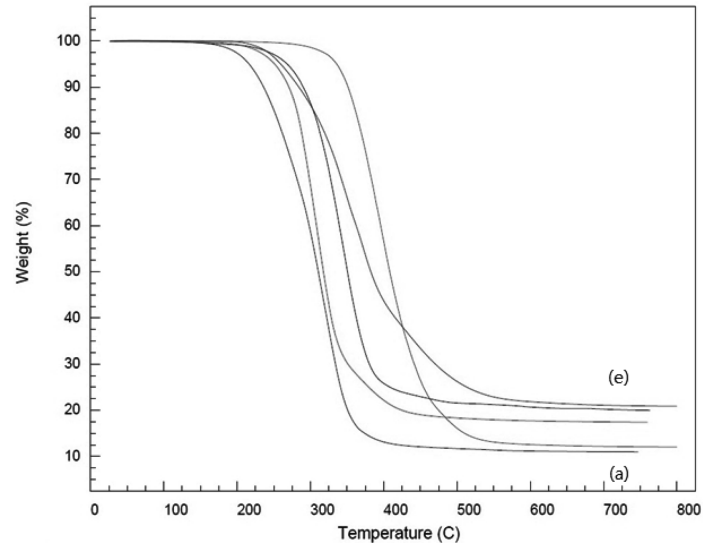

Fig. 2. TGA Thermograms of poly(dialkyl)silanes under $\mathrm{N}_{2}$. (a) methylhexyl, $11.0 \%$ (b) dioctyl, $12.0 \%$ (c) dihexyl, $17.4 \%$ (d) methylphenyl, $20.0 \%$ (e) dipentyl, $20.8 \%$

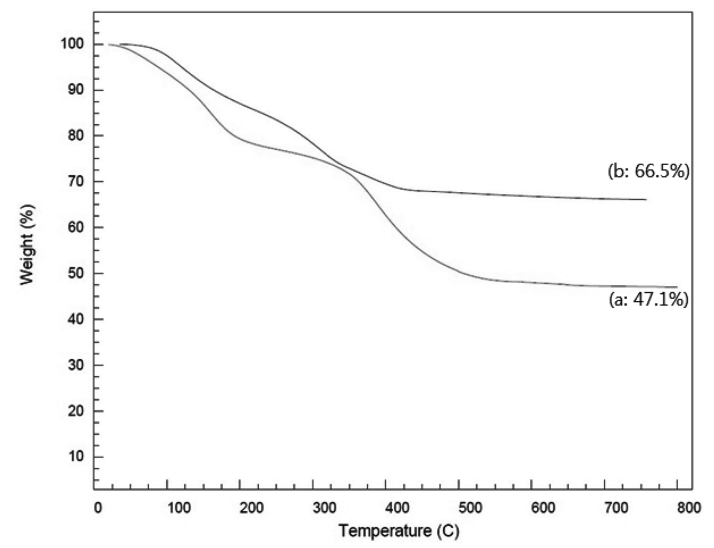

Fig. 3. TGA Themograms of polyphenylsilane. (a) and polymethylsilane (b) under $\mathrm{N}_{2}$

IR 펠렛 프레스(pellet press)를 사용하여 압축하면서 동 시에 진공 펌프로 30 분 동안 용매를 제거하면서 얻은 디스크를 작은 조각으로 나누어 질소 대기 하에서

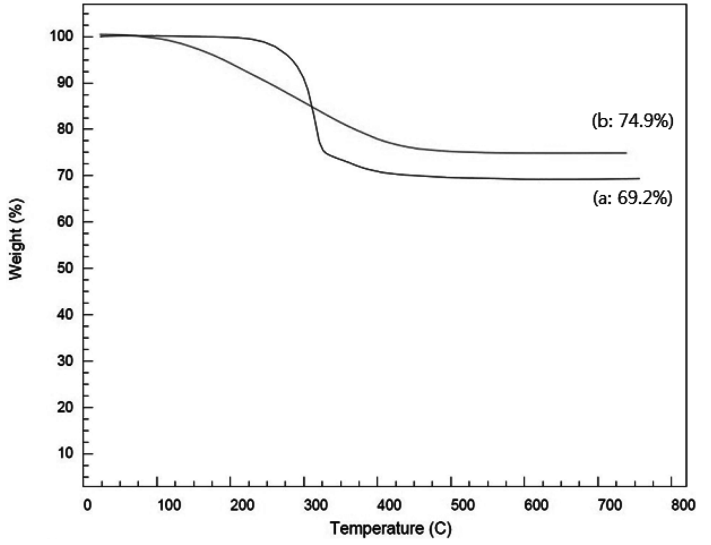

Fig. 4. TGA Thermograms of poly(dihexyl)silane/SiC pellet. (a) and poly(dipentyl)silane/SiC pellet (b) under $\mathrm{N}_{2}$

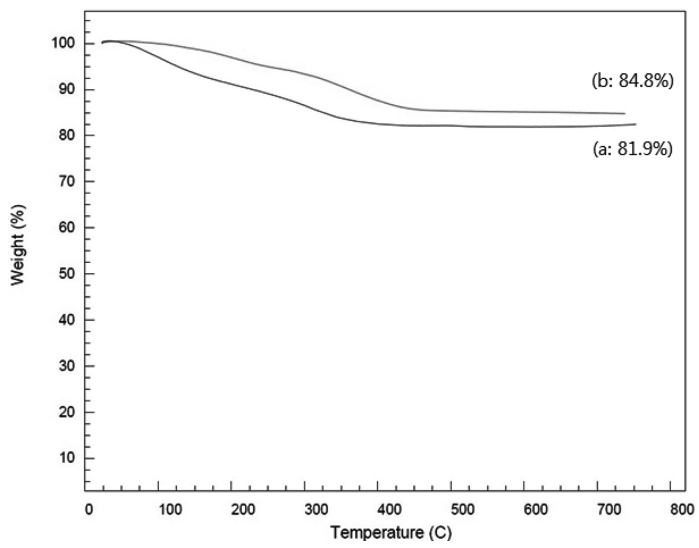

Fig. 5. TGA Thermograms of polymethylsilane/ $\mathrm{SiC}$ pellet. (a) and polyphenylsilane/SiC pellet (b) under $\mathrm{N}_{2}$

TGA로 열에 의한 변화를 조사하였다(Fig. 4, 5). 열처 리 과정 이후에도 열분해 전 모양을 그대로 유지한 디 스크 시료들의 SEM사진은 Fig. 6에 정리하였다. 
(a)

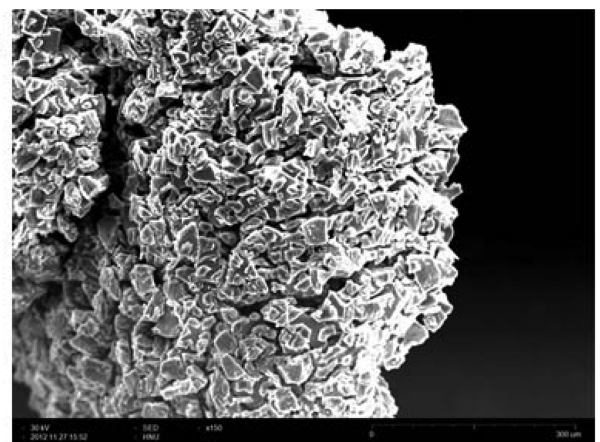

(c)

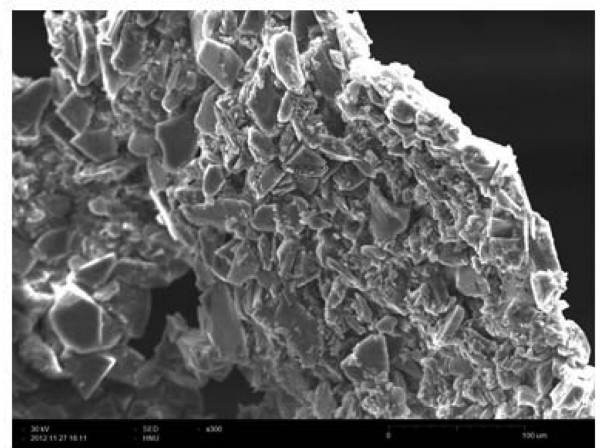

(b)

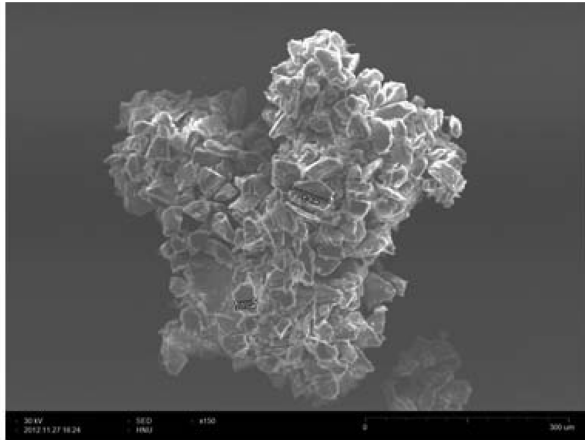

(d)

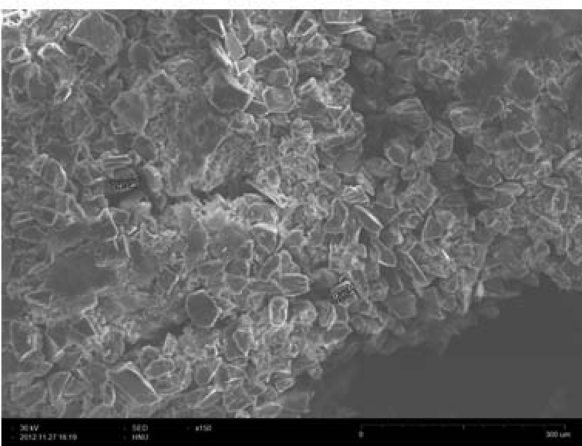

Fig. 6. SEM images of polyalkylsilane/SiC pellet after TGA under $\mathrm{N}_{2}$. (a) polyphenylsilane (b) polymethylsilane (c) poly(dipentyl)silane (d) poly(dihexyl) silane

\section{3. 결과 및 고찰}

\section{1. 폴리알킬실란의 합성}

본 연구에서 초음파 반응 장치를 이용한 폴리(디알 킬)실란의 합성은 일반적으로 $70 \%$ 에서 $90 \%$ 사이의 총 수득율을 보여 주었으며 이전에 열적 합성법에 의 한 비교적 간단한 알킬기를 갖는 폴리디알킬실란의 합성의 경우 $60-80 \%$ 의 수득률과 비교해 볼 때 높은 수득률을 보여주고 있는 데 이는 본 연구에서 사용한 디알킬실란의 경우 크기가 큰 유기 치환기의 영향으 로 꼻는점이 상승하여 용매인 톨루엔의 꼻는 점에서 의 반응온도에서 증발된 출발물질의 손실이 감소한 것도 한 요인이라고 생각되었다. 그러나 총수득률은 비교적 증가하였어도 재결정을 통한 고분자량 성분의 고체 수득률은 일반적으로 감소한 것으로 보이는 데 이는 알킬실란 치환기의 유기화합물적 성질의 증가로 인한 재결정 용매에서의 용해도 증가 요인으로 여겨 진다.

메틸- 또는 페닐트리염화실란을 이용한 폴리(모노알 킬)실란 (방향족이기는 하지만 페닐기를 포함해서 함 께 지칭하였음) 경우 폴리페닐실란은 $90 \%$ 의 높은 수
율을 보이는 것은 폴리디알킬실란 합성 경우와 비슷 한 경향성이라고 생각되는 반면 폴리메틸실란은 조심 스럽게 진행시킨 반응과정에도 불구하고 불용성 고체 의 형성으로 $40 \%$ 대의 낮은 수득률을 보였으며 이는 역시 3차원 네트워크 구조의 영향으로 생각되었다. 하 지만 열적 반응의 경우 거의 모든 생성물이 불용성 고체인 것을 감안하면 비록 그 분자 크기는 크지 않 을지라도 가공성의 폴리메틸실란을 합성할 수 있었다 는 것이 특징으로 볼 수 있다.

일반적으로 재결정된 폴리디알킬실란들과 폴리알킬 실란 중 폴리페닐실란은 무게 평균 분자량 $M_{w}$ 이 $10^{4}$ 정도였으며, 이는 UV 최대흡수파장 $\left(\lambda_{\max }\right)$ 이 $300 \mathrm{~nm}$ 부근으로 비교적 $\lambda_{\max }$ 가 폴리실란 고분자 사슬의 길이 에 비례하는 것을 고려할 때 일치하는 결과라고 생각 되었다. 또한 이들 폴리실란들은 다양한 유기용매에 잘 녹는 가용성을 가져 폴리머 침투를 통한 세라믹 복합체 응용에 이용할 수 있음을 확인하였다.

\section{2. 폴리알킬실란의 열적 성질}

세라믹 복합체 응용을 위한 폴리알킬실란의 열적 성질에서 가장 주목해야 할 성질은 열분해 잔류물 비 
율이다. Fig. 2에서는 폴리(디알킬)실란의 TGA 열적 변화를 볼 수 있는데 공통적으로 약 $250{ }^{\circ} \mathrm{C}$ 에서부터 시작한 열분해는 약 $400{ }^{\circ} \mathrm{C}$ 까지 급격한 무게 감소를 보여 주어 활발한 분해 과정이 있음을 알 수 있었고 $500{ }^{\circ} \mathrm{C}$ 이후에서는 열분해가 완료되고 일정 무게의 잔류물이 유지되는 것으로 나타났다. 잔류물 비율은 예상한대로 $10-20 \%$ 정도의 낮은 결과를 보여 주었다. 조금 더 다양한 유기 치환기를 도입하고 폴리실란의 형성 이후 가교반응이 가능하다면 잔류물 비율은 증 가시킬 수 있을 것으로 예상하였다. Fig. 3에서의 폴 리(모노알킬)실란의 TGA 열적 변화에서는 예상되는 3 차원 네트워크 구조 때문에 잔류물 비율이 폴리페닐 실란은 $47.5 \%$, 폴리메틸실란은 더 증가하여 $66.5 \%$ 의 잔류물 비율을 얻을 수 있었다. 역시 선형 사슬 구조 보다는 가교결합과 같은 3 차원 네트워크 구조가 잔류 물 비율을 높이는데 필요하다는 것을 확인할 수 있었 고, 특히 폴리메틸실란의 경우에는 비록 합성의 어려 움과 생성물의 안정성이 제한적이기는 하지만 $\mathrm{C}: \mathrm{Si}$ 비가 $1: 1$ 로서 만일 탄소 잔류물의 존재가 바람직하지 않는 경우에는 이상적인 조성의 물질이 될 것이다. 이 들 폴리알킬실란들의 TGA 잔류물들에 대한 XRD 분 석은 특별한 결정성 피크를 주지 않아 무정형으로 여 겨졌으며 TGA 상한 온도인 700-800 ${ }^{\circ} \mathrm{C}$ 까지는 특별한 소결과정 등이 발생하지 않은 것이라고 판단되었다.

\section{3. 폴리알킬실란의 응용}

비교적 낮은 열분해 잔류물 비유임에도 가용성과 같은 가공성 등의 물성으로 세라믹 복합체의 응용을 조사하였다. 상업용 $\mathrm{SiC}$ 분말(Aldrich Chemical Co.) 과 균일하게 섞어서 펠렛 디스크로 성형한 다음 디스 크의 열분해 과정과 열분해 후의 변형을 보았는데, 디 스크 모두 약 $800{ }^{\circ} \mathrm{C}$ 까지의 열 처리과정에서 제 모양 을 그대로 유지하였다. Fig. 4의 폴리(디헥실)실란/SiC 와 폴리(디펜틸)실란/SiC 디스크의 $\mathrm{TGA}$ 결과에서는 $\mathrm{SiC}$ 분말을 제외한 폴리(디알킬)실란의 잔류물 비율이 각각 $7.5 \%$ 와 $24.6 \%$ 로, 유기치환기의 유사성에도 불구 하고 폴리(디알킬)실란만의 잔류물 비율 $17.4 \%$ 에서 감소하거나 $20.8 \%$ 에서 증가하는 이유를 찾기 어려운 결과를 보여 주었다. 반면에 Fig. 5의 폴리메틸실란/ $\mathrm{SiC}$ 와 폴리페닐실란/SiC 디스크의 $\mathrm{TGA}$ 결과에서는 $\mathrm{SiC}$ 분말을 제외한 폴리(모노알킬)실란의 잔류물 비율 이 각각 $45.6 \%$ 와 $66.5 \%$ 로, 폴리(모노알킬)실란만의 잔류물 비율 $45.6 \%$ 와 비슷하거나 $54.4 \%$ 로 상대적으 로 약간 감소하여 비교적 안정적인 응용성을 생각할
수 있었다. 폴리(디알킬)실란의 경우에는 잔류물 비율 이 상대적으로 많이 낮아 오차의 범위가 더 클 수 있 다고 생각되었다.

이들 열처리한 디스크들의 모습을 Fig. 6의 SEM 이미지로 확인하였다. 상업용 $\mathrm{SiC}$ 입자의 모습이 선명 하게 남아 있지만 펠렛 프레스로 압축 성형한 모습이 그대로 남아 있어 이들 폴리실란들의 폴리머 흡착을 통한 세라믹 복합체 응용의 가능성을 확인할 수 있었 다. 이들 디스크들의 XRD 분석은 $\mathrm{SiC}$ 분말 자체의 결정성 외에 폴리알킬실란 자체만의 TGA와 같이 폴 리알킬실란의 열분해 잔류물에 의한 특별한 결정성 피크를 주지 않았다. 결정성의 형성을 위해 더 높은 온도에서의 용융 융합 등에 대한 연구가 진행 중이다.

\section{4. 결 론}

유기염화실란을 원료물질로 사용하고 초음파 반응 방법을 이용한 Wurtz 탈염소축합반응으로 알칼리 금 속과 반응시켜 폴리(디알킬)실란과 폴리(모노알킬)실 란을 합성하고 이들의 열적 성질을 TGA로 조사하여 각각 $10-20 \%$ 와 $40-60 \%$ 의 잔류물 비율을 얻었고 상업 용 $\mathrm{SiC}$ 분말과 함께 펠렛 디스크를 성형하여 열분해 과정과 $\mathrm{SEM}$ 이미지로 세라믹 복합체용 응용 가능성 을 확인할 수 있었다. 본 연구에서는 열분해 잔류물로 탄소의 존재가 확실하여 성분조사는 하지 않았지만 앞으로 원소분석 등을 통해 잔류물의 조성까지도 함 께 연구하고자 하며 상업적 이용 등을 위해 조금 더 큰 규모의 실험 조건 확립과 특히 결정성의 형성을 위한 열분해 실험 조건의 확립에 대해 연구를 진행 중이다.

\section{감사의 글}

본 연구에서 폴리실란의 합성은 미국 University of Wisconsin-Madison 화학과 Robert West 교수의 Organosilicon Research Center에서 수행하였으며 감 사를 드립니다.

\section{참고문헌}

1. S.-A. Ahn, S.-H. Lee, Y. S. Song and G.-H. Lee, Anal. Sci. Tech., 24, 105 (2011).

2. E.-O. Yang, J.-K. Lee, S.-H. Lee, Y. S. Song and G.-H. Lee, Anal. Sci. Tech., 19, 504 (2006).

Analytical Science \& Technology 
3. L. Liu, X. Li, X. Xing, C. Zhow and H. Hu., J. Organomet. Chem., 693, 917 (2008).

4. H. K. Kim and K. Matyjaszewski, J. Am. Chem. Soc., 110, 3321 (1988)

5. K. Matyjaszewski, D. Greszta, S. H. Jeffrey and H. K. Kim, Macromolecules, 28, 59 (1995).

6. R. Kani, Y. Nakano, H. Yoshida, S. Mikoshiba and S. Hayase, J. Polymer Sci.: Pare A. Polym. Chem., 35, 2355 (1997).

7. R. D. Miller, D. Thomson, R. Sooriyakumaran and G. N. Fickes, J. Polym. Sci., Part A, Polym. Chem., 29, 813 (1991)
8. M. Suzanne, W. Bushnell, J. M. Michael and H. S. John, Polymer, 37, 2067 (1996).

9. S. Yajima, J. Hayashi and M. Omori, Chem. Lett., 931 (1975).

10. K. S. Mazdiyasni, R. West and L. D. David, J. Am, Ceram. Soc., 61, 504 (1978).

11. R. E. Trujillo, J. Organomet. Chem., 198, C27 (1980).

12. I. N. Jung, G.-H. Lee, M. Y. Suk and S. H. Yeon, Bull. Korean Chem. Soc., 12, 706 (1991).

13. S. H. Jang, C. K. Park, Y. S. Song and G.-H. Lee, Bull. Korean Chem. Soc., 17, 443 (1996). 